\title{
INDICADORES DE DESENVOLVIMENTO SUSTENTÁVEL: ESTUDO COMPARATIVO ENTRE BRASIL E SUÍÇA
}

\author{
Márcia França Ribeiro Fernandes dos Santos \\ José Antonio Assunção Peixoto
}

Leyderdavan de Souza Xavier

\section{RESUMO}

O objetivo deste trabalho é apresentar um estudo da estrutura dos indicadores de desenvolvimento sustentável adotada pela Fundação Instituto Brasileiro de Geografia e Estatísticas (IBGE) e pelos órgãos suíços que desenvolveram o modelo Monitoring Sustainable Development (MONET) cujas publicações encontram-se disponíveis da Internet. Para alcançar tal objetivo elabora-se uma revisão bibliográfica sobre o tema e, em seguida, comparam-se os marcos ordenadores e conceituais adotados em ambas as propostas, avaliando-se os aspectos que apresentam convergências e divergências do ponto de vista teórico e metodológico levando-se em consideração as particularidades de cada país.

Palavras-chave: Indicadores. Desenvolvimento sustentável. Brasil. Suíça.

\begin{abstract}
The aim of this paper is to present a study of the structure of indicators of sustainable development adopted by the Brazilian Institute of Geography and Statistics (IBGE) and the Swiss authorities who developed the model Monitoring Sustainable Development (MONET) whose publications are available on the Internet. To achieve this goal prepares itself a literature review on the subject, and then compare themselves officers and the landmarks used in both conceptual proposals by evaluating whether the things that have similarities and differences from a theoretical and methodological taking It is into consideration the particularities of each country.
\end{abstract}

Keywords: Indicators. Sustainable development. Brazil. Switzerland. 


\section{INTRODUÇÃO}

O século XX foi palco de transformações significativas em todas as dimensões da vida humana (HOBSBAWN, 1996 apud BELLEN, 2007). O período foi marcado por um exponencial avanço tecnológico, que provocou o aumento da expectativa de vida do homem, bem como de sua capacidade de autodestruição, trazendo como conseqüências o crescimento significativo da utilização de matéria e de energia para atender as necessidades da sociedade (BELLEN, 2007).

O cenário mundial apresentava um aumento na demanda por bens e serviços, mas seu preenchimento não foi uniforme e gerava grandes disparidades nos padrões de vida e de consumo das populações de diferentes nações, juntamente com índices de desigualdade crescentes (BELLEN, 2007).

Para medir o crescimento da economia, expresso através da capacidade de uma nação de gerar riqueza interna, foi criado o Produto Interno Bruto (PIB) que segundo BELLEN (2005 apud MARTINS, 2006 p. 25) representa "uma medida de quão rápido os recursos são transformados em fluxos monetários sem considerar os efeitos específicos na sociedade". No entanto, tal indicador apresentava lacunas com relação aspectos sociais.

Para monitorar os problemas sociais oriundos da desigualdade da distribuição de renda, durante os anos 60, deu-se início ao desenvolvimento de sistemas de indicadores sociais, envolvendo aspectos como saúde, educação, equidade, trabalho e rendimento, perdendo o PIB sua exclusividade (SCANDAR NETO, 2004). As discussões passaram a ser focadas não no que ocorria nos paises mais ricos, mas naqueles que apresentassem melhor qualidade de vida.

Nessa mesma época, a indústria de bens e consumo dos países mais desenvolvidos requeria energia em grande quantidade para manter o crescimento econômico desejado; e energia em parte significa a emissão de poluentes (MARTINS, 2006) que podem comprometer a manutenção da vida na Terra. 0 marco inicial para a incorporação da questão ambiental no debate sobre o desenvolvimento das nações aconteceu com a primeira Conferência da Organização das Nações Unidas (ONU) sobre o Meio Ambiente Humano realizada em Estocolmo no ano de 1972. "Essa conferência chamou a atenção das nações para o fato de que a ação humana estava causando séria degradação da natureza e criando severos riscos para o bem estar e para a própria sobrevivência humana" (FELDMAN, 1997 p. 14). Este evento foi a primeira iniciativa global visando identificar os impactos da ação do homem sobre o meio ambiente, bem como propor a adoção de um modelo de desenvolvimento que respeitasse a capacidade de renovação dos ecossistemas em substituição ao modelo fundamentado apenas no crescimento econômico (FELDMAN, 1997).

Este cenário global serviu de motivação para o surgimento de um novo paradigma de desenvolvimento denominado sustentável. De acordo com essa idéia o grau de avanço de uma dada sociedade é medido não somente por sua capacidade de gerar riqueza (dimensão econômica), mas também pelas condições de divisão da riqueza gerada (dimensão social) juntamente com a preservação e conservação do meio ambiente (dimensão ambiental).

Scandar Neto (2006) afirma que o desenvolvimento sustentável ainda não é um conceito e sim uma idéia, uma vez que o fenômeno se revela complexo e envolve a integração de suas dimensões. A complexidade da sustentabilidade é reforçada por Hahn (2002 apud SCANDAR NETO, 2006, p.13), para quem ela "não é uma coisa a ser atingida, mas sim um processo contínuo". Dentro desta linha de pensamento é possível que o desenvolvimento sustentável nunca venha a se tornar um conceito fechado porque o mesmo evolui à medida que as 
práticas sociais se transformam pela ação reflexiva de atores (GIDDENS, 2003).

Face ao exposto, como mensurar um conceito que ainda está em formação? A Comissão de Desenvolvimento Sutentantável (CDS) da Organização das Nações Unidas (ONU) entendeu que para medir esse fenômeno tornou-se necessário elaborar um sistema de indicadores envolvendo as três dimensões acima citadas. No entanto, a mensuração de tais dimensões tem se mostrado uma tarefa complexa, considerando as especificidades dos diferentes países.

Nações como a Suíça preferiram desenvolver um ferramental próprio para acompanhar se seu desempenho está ocorrendo de forma sustentável (ALTWEGG et al., 2004). No caso brasileiro, optou-se por realizar algumas simplificações do sistema de indicadores propostos pela CDS/ONU.

Nesse contexto, o presente artigo tem como objetivo fazer um estudo da estrutura dos indicadores de desenvolvimento sustentável adotada pela Fundação Instituto Brasileiro de Geografia e Estatísticas (IBGE) e pelos órgãos suíços que desenvolveram o modelo Monitoring Sustainable Development (MONET) cujas publicações encontram-se disponíveis da Internet através dos sites www.ibge.gov.br e www.bfs.admin.ch. Para alcançar tal objetivo elabora-se uma revisão bibliográfica sobre o tema e, em seguida, comparam-se os marcos ordenadores e conceituais adotados nas propostas de construção de indicadores de desenvolvimento sustentável (IDS), tanto de Brasil quanto da Suíça, avaliando-se os aspectos que apresentam convergências e divergências do ponto de vista teórico e metodológico, levando-se em consideração as particularidades de cada país.

\section{DESENVOLVIMENTO SUSTENTÁVEL: UM CONCEITO EM CONSTRUÇÃO}

Para Bellen (2007, p.23) “o conceito de desenvolvimento sustentável provém de um (...) processo histórico de reavaliação crítica da relação existente entre a sociedade civil e seu meio natural. Por se tratar de um processo contínuo e complexo, observa-se hoje que existe uma variedade de abordagens que procura explicar o conceito" e essa variedade pode ser demonstrada pelo enorme número de definições presentes na literatura.

O uso do termo desenvolvimento sustentável surgiu em 1980 no documento World conservation strategy: living resourse conservation for sustainable development elaborado em cooperação pelas seguintes instituições: International Union for Conservation of Nature and Natural Resource (IUCN), Programa das Nações Unidas para o Meio Ambiente (PNUMA), World Wildlife Fund (WWF), Food and Agriculture Organization (FAO) e United Nations Educational, Scientific and Cultural Organization (UNESCO) (WORLD, 1980 apud SCANDAR NETO, 2006). Tal publicação relata que para ser sustentável o desenvolvimento deve considerar as três dimensões: social, ecológica e econômica (BELLEN, 2002 apud SCANDAR NETO, 2006).

Ao longo dos anos, o termo foi evoluindo com diversos focos e conceituações; no entanto, ainda se considera o desenvolvimento sustentável uma idéia em formação e não um conceito plenamente elaborado. A definição constante do Relatório de Brundtland (INDICADORES ...,2004 p. 10) é a mais conhecida e relata que "desenvolvimento sustentável (...) é aquele que atende às necessidades do presente sem comprometer a possibilidade de as gerações futuras atenderem as suas próprias necessidades". Atualmente, a preocupação é mais ampla e se estende a própria sobrevivência do planeta.

Pronk e ul Haq (1992 apud BELLEN, 2007) salientam o papel do crescimento econômico para a sustentabilidade. "Para eles, o desenvolvimento é sustentável quando o crescimento 
econômico traz justiça e oportunidades para todos os seres humanos do planeta, sem privilégio de algumas espécies, sem destruir os recursos naturais e sem ultrapassar a capacidade de carga do sistema" (BELLEN, 2007 p. 23-24).

No entanto, por muito tempo o desenvolvimento permaneceu como sinônimo de crescimento econômico (SCANDAR NETO, 2004). No tocante ao desenvolvimento econômico, o filósofo Vieira Pinto (2005 p.303) nos remete à seguinte distinção entre os termos crescimento e desenvolvimento: "enquanto o crescimento tem caráter quantitativo, conservador, meramente expansivo e se faz em progressão aritmética, o desenvolvimento exprime-se como qualitativo, transformador da realidade, e se faz em progressão geométrica. Diferem ainda no aspecto humano; o primeiro favorece uma minoria, ao passo que o verdadeiro desenvolvimento tem papel universalmente libertador".

O caráter dinâmico do conceito é ressaltado por Bossel (1998, 1999 apud BELLEN, 2007 p. 29) que "afirma que o conceito de desenvolvimento sustentável deve ser dinâmico. A sociedade e o meio ambiente sofrem mudanças contínuas, as tecnologias, culturas, valores e aspirações se modificam constantemente e uma sociedade sustentável deve permitir e sustentar essas modificações".

Além disso, e reforçando o caráter dinâmico da sustentabilidade, Svedin (1987 apud SACHS, 1997 p. 474) afirma que "o desenvolvimento sustentável não representa um estado estático de harmonia, mas, antes, um processo de mudança, no qual a exploração dos recursos, a dinâmica dos investimentos, e a orientação das inovações tecnológicas e institucionais são feitas de forma consistente face às necessidades tanto atuais quanto futuras".

Dentro dessa perspectiva dinâmica fundamentada em um processo de mudança, Sachs (1997 p. 474 475) aponta que o conceito de desenvolvimento sustentável apresenta cinco dimensões principais:

a. Sustentabilidade social, isto é, o estabelecimento de um processo de desenvolvimento que conduza a um padrão estável de crescimento, com uma distribuição mais eqüitativa da renda e dos ativos, assegurando uma melhoria substancial dos direitos das grandes massas da população e uma redução das atuais diferenças entre os níveis de vida daqueles que têm e daqueles que não têm.

b. Sustentabilidade econômica, tornada possível graças ao fluxo constante de inversões públicas e privadas, além da alocação e do manejo eficientes dos recursos naturais.

c. Sustentabilidade ecológica, implicando a expansão da capacidade de transporte da "nave espacial terrestre", mediante a intensificação dos usos do potencial de recursos existentes nos diversos ecossistemas, intensificação esta tornada compatível com um nível mínimo de deterioração deste potencial. 0 consumo de combustíveis fósseis e outros, de esgotamento rápido além de prejudiciais ao meio ambiente, deveria ser reduzido.

d. Sustentabilidade geográfica: os problemas ambientais são ocasionados, muitas vezes, por uma distribuição espacial desequilibrada dos assentamentos humanos e das atividades econômicas. Dois exemplos expressivos desta tendência são a excessiva concentração da população em áreas metropolitanas, e a destruição de ecossistemas frágeis, mas de importância crucial, devido a processos não controlados de colonização. Daí a necessidade de se buscar uma configuração rural-urbana mais equilibrada e de se estabelecer uma rede de reservas da bioesfera para proteger a diversidade biológica, e, ao mesmo tempo, ajudar a 
população local a viver melhor.

e. Sustentabilidade cultural, que talvez, constitua a dimensão mais difícil de ser concretizada, na medida em que implica que o processo de modernização deveria ter raízes endógenas, buscando a mudança em sintonia com a continuidade cultural vigente em contextos específicos.

Os autores Lage \& Barbieri (2001 apud SCANDAR NETO, 2006) acrescentam ainda mais duas dimensões àquelas propostas por Sachs: a dimensão tecnológica que se refere à promoção do desenvolvimento científico e tecnológica local; e a dimensão política que se refere à criação de condições que permitam a participação efetiva no planejamento e controle social das políticas públicas por parte da sociedade civil.

Embora os estudos acima mencionados tenham considerado a existência de até sete dimensões da sustentabilidade, o que tem prevalecido nos estudos envolvendo o desenvolvimento sustentável é tripé envolvendo as dimensões ambiental, social e econômica do desenvolvimento sustentável, na qual a sociedade busca o equilíbrio entre o que é socialmente desejável, economicamente viável e ecologicamente sustentável.

\section{INDICADORES DE SUSTENTABILIDADE}

As instituições de estatísticas públicas são responsáveis pela mensuração do "desenvolvimento sustentável". No entanto, como mensurar um, "conceito" que, conforme abordado anteriormente, ainda está em formação? A solução vem através do desenvolvimento de ferramentas de gestão que monitorem características indicativas do que se considera sustentabilidade; as ferramentas mais utilizadas são o uso de indicadores de desempenho estruturados com o objetivo de "agregar e quantificar informações de modo que sua significância fique mais aparente". Os indicadores "simplificam as informações sobre fenômenos complexos tentando melhorar com isso o processo de comunicação" (BELLEN, 2007 p.42).

Quiroga (2001 apud SCANDAR NETO, 2006) em seus estudos propõe uma taxionomia de IDS fundamentada no enfoque metodológico, que pode ser classificado como: sistêmico, quando se refere à apresentação conjunta de uma lista de indicadores baseados em um marco conceitual; e comensuralista, quando resume os diversos indicadores a um número único. Alguns estudiosos entendem que para acompanhar e medir tal fenômeno é necessário um sistema de indicadores fundamentado em um marco conceitual previamente estabelecido como, por exemplo, o proposto pela CDS/ONU. Outros argumentam que devido à complexidade do fenômeno é melhor a adoção de indicadores sintéticos que são resumidos em um número único. Tanto os sistemas de indicadores como os chamados indicadores sintéticos apresentam vantagens e desvantagens do ponto de vista de sua utilização como forma de mensurar o grau de desenvolvimento sustentável de uma nação.

Para Scandar Neto (2006 p.32) o sistema de indicadores é definido como "um conjunto de indicadores que devem ser analisados separadamente, mas cujo conjunto apontaria para uma evolução no sentido de desenvolvimento sustentável". No entanto, como o conceito ainda está em formação cabe destacar que tal conjunto deve ser analisado de modo a promover a perfeita integração entre as dimensões de sustentabilidade. Nesse sentido tais sistemas de indicadores de desenvolvimento sustentável podem ser entendidos como artefatos técnicos "com os quais o homem realiza vida, produz e, ao mesmo tempo, cria espaço". Portanto, meios instrumentais de reprodução das práticas sociais (SANTOS, 2006 p. 29). 
De acordo com Dahl (1997 apud BELLEN, 2007) o grande desafio se constitui na compreensão do desenvolvimento sustentável com suas dimensões e complexidade inerentes, bem como na utilização de indicadores para sua mensuração. Para o autor, o fenômeno da sustentabilidade deve ser explorado de forma dinâmica e os indicadores de desenvolvimento devem fornecer um retrato, ou melhor, um filme, da situação de uma maneira simples.

Tal autor ainda ressalta "a diferença dos países, a questão da diversidade cultural, o conflito norte-sul e os diferentes graus de desenvolvimento como importantes fatores na construção dos indicadores" (DAHL, 1997 apud BELLEN, 2007 p.53). Como anteriormente citado a CDS/ONU elaborou um sistema de IDS, a partir de marco conceitual e teórico bem definido, de modo a monitorar os progressos obtidos pelas nações no caminho de um futuro sustentável. Alguns países, como o Brasil, seguiram este modelo; no entanto, nações como a Suíça optaram por desenvolver um ferramental próprio para acompanhar se seu desempenho está ocorrendo de forma sustentável (ALTWEGG et al., 2004).

\section{SOBRE A ESTRUTURA DE IDS}

Para se estudar a estrutura dos IDS propostas neste estudo, é necessário abordar questões como a definição de marco ordenador e marco conceitual - também conhecido como marco sistêmico.

Scandar Neto (2006, p. 38) afirma que o marco ordenador "pode ser uma simples proposta de classificação dos indicadores segundo temas e sub temas". Este marco passa a ser conceitual quando está "intimamente relacionado a uma concepção teórica específica sobre o fenômeno estudado, facilitando assim a interpretação destes indicadores dentro da lógica e dos paradigmas próprios desta concepção" (SCANDAR NETO, 2006 p. 38).

\section{Estrutura de ids proposta pela CDS/ONU}

Como resultado da Conferência Rio 92 foi formulado um documento denominado Agenda 21 que especificou em seus capítulos 8 e 40 questões referentes à relação entre meio ambiente, desenvolvimento sustentável e informações para tomada de decisões. Um ponto que ganhou destaque foi o reconhecimento da importância dos indicadores em ajudar as nações a tomar decisões em relação ao desenvolvimento sustentável (RIBEIRO, 2004).

A construção de uma proposta de sistema de IDS ficou sob a responsabilidade da CDS/ONU em parceria com governos nacionais, instituições acadêmicas, organizações não governamentais, organizações do sistema da ONU e especialista em todo mundo (RIBEIRO, 2004). Os esforços foram direcionados no sentido da harmonização de indicadores de desenvolvimento sustentável em níveis nacionais, regionais e globais, incluindo a incorporação de um conjunto de indicadores em comum, regularmente atualizados e amplamente divulgados (INDICATORS OF SUSTAINABLE DEVELOPMENT, 2001).

A CDS/ONU, em 1996, publicou o documento Indicadores de desarollo sostenible: marco y metodologias, conhecido como Livro Azul, no qual propunha um conjunto de 143 indicadores, que quatro anos mais tarde, foram reduzidos para 57 (MARTINS, 2006).

Segundo Ribeiro (2004) esta publicação é o consenso oriundo de diversas instituições para o desenvolvimento de um conjunto de indicadores que tem por objetivo auxiliar a melhor compreensão das várias dimensões do fenômeno do desenvolvimento sustentável e as suas complexas interações que ocorrem entre tais dimensões. Ainda de acordo com o autor tal publicação “é o ponto de partida e uma ferramenta flexível para orientar os países que 
queiram desenvolver seus programas nacionais utilizando indicadores para medir o progresso em direção ao desenvolvimento sustentável" (RIBEIRO, 2004 p.53).

Com relação ao marco conceitual adotado, a CDS/ONU primeiramente organizou os capítulos da Agenda 21 de acordo com as quatro dimensões primárias do desenvolvimento sustentável - social, econômica, ambiental e institucional. Segundo Indicators of Sustainable Development (2001) "dentro destas categorias, os indicadores foram classificados de acordo com suas características de pressão, estado e resposta; adotando uma aproximação conceitual largamente usada para indicadores de desenvolvimento ambiental".

Desta forma, foi utilizada a estrutura conceitual do modelo Pressão-Estado-Resposta (PER) formulada por Friends e Raport em 1979. Tal modelo é fundamentado no conceito de causalidade, ou seja, "as atividades humanas exercem pressão sobre o meio ambiente, pressão que pode provocar alterações em seu estado, e a sociedade adota resposta para enfrentar as conseqüências negativas das pressões exercidas" (RIBEIRO, 2004 p.52).

Com base nesta fundamentação conceitual a CDS/ONU adaptou a estrutura do modelo PER para o sistema de IDS no qual: os indicadores de pressão representam as atividades, processos e padrões humanos que impactam tanto positivamente como negativamente o desenvolvimento sustentável; os indicadores de estado fornecem uma leitura da condição do desenvolvimento sustentável; e os indicadores de resposta representam as ações sociais visando o desenvolvimento sustentável (INDICATORS OF SUSTAINABLE DEVELOPMENT, 2001).

No entanto, após testar esta metodologia em alguns países de modo a avaliar a aplicabilidade da estrutura proposta, "alguns países concluíram que o quadro de referência pressão estadoresposta, embora aceitável em um contexto ambiental, não era apropriado para as dimensões social, econômica e institucional do desenvolvimento sustentável" (INDICATORS ...., 2001).

Scandar Neto (2006) ressalta que a sociedade não pode ser vista como uma entidade externa que exerce pressão ou é agente de respostas que atenuam as pressões; dentro do contexto do desenvolvimento sustentável, a sociedade é parte integrante do sistema.

Desta forma, o marco conceitual foi reformulado de modo a enfatizar temas principais relacionados ao desenvolvimento sustentável, com a limitação do número de indicadores para alcançar um conjunto principal. A estrutura conceitual buscava refletir as conexões entre dimensões, temas e sub-temas, bem como os objetivos do desenvolvimento sustentável para o avanço social e desenvolvimento institucional, sem comprometer o meio ambiente e garantindo a prosperidade econômica (INDICATORS OF SUSTAINABLE DEVELOPMENT, 2001). A Tabela 1 apresenta os marcos ordenadores adotados pela CDS/ONU (temas e sub temas): 
Tabela 1 - Marco ordenador proposto pela CDS/ONU

\begin{tabular}{|c|c|}
\hline \multicolumn{2}{|r|}{ Dimensão: Social } \\
\hline Tema & Sub tema \\
\hline Equidade & Pobreza; Igualdade de Gênero \\
\hline Saúde & $\begin{array}{lll}\text { Estado Nutricional; Mortalidade; Saneamento; Água } \\
\text { Potável; Cuidados com a saúde }\end{array}$ \\
\hline Educação & Nível de Educação; Proficiência \\
\hline Habitação & Condições de Habitação \\
\hline Segurança & Crime \\
\hline População & Mudança Populacional \\
\hline \multicolumn{2}{|r|}{ Dimensão: Ambiental } \\
\hline Tema & Sub tema \\
\hline Atmosfera & $\begin{array}{l}\text { Mudança Climática; Destruição da Camada de Ozônio; } \\
\text { Qualidade do Ar }\end{array}$ \\
\hline Terra & Agricultura; Florestas; Desertificação; Urbanização \\
\hline $\begin{array}{l}\text { Oceanos, Mares e Áreas } \\
\text { Costeiras }\end{array}$ & Zona Costeira; Pesca \\
\hline Água Doce & Quantidade de água; Qualidade da água \\
\hline Biodiversidade & Ecossistema; Espécies \\
\hline \multicolumn{2}{|r|}{ Dimensão: Econômica } \\
\hline Tema & Sub tema \\
\hline Quadro Econômico & Desempenho Econômico; Comércio; Estágio Financeiro \\
\hline $\begin{array}{l}\text { Padrões de Produção e } \\
\text { Consumo }\end{array}$ & $\begin{array}{l}\text { Consumo Material; Uso de Energia; Geração e } \\
\text { Gerenciamento da água; Transporte }\end{array}$ \\
\hline \multicolumn{2}{|r|}{ Dimensão: Institucional } \\
\hline Tema & Sub tema \\
\hline Quadro Institucional & $\begin{array}{l}\text { Implementação de estratégias de desenvolvimento } \\
\text { sustentável; Cooperação Internacional }\end{array}$ \\
\hline Capacidade Institucional & $\begin{array}{l}\text { Acesso a Informação; Infra-estrutura de comunicação; } \\
\text { Ciência e Tecnologia; Preparação e Resposta para desastres }\end{array}$ \\
\hline nte: CSD Theme Indicator & nework, 2007 \\
\hline
\end{tabular}




\section{Estrutura de IDS adotada no Brasil}

O trabalho de construção de IDS no Brasil ficou sob a responsabilidade do órgão oficial de estatística do governo, o IBGE. De modo a atender as disposições da Agenda 21, o referido instituto reuniu esforços e editou a publicação Indicadores de desenvolvimento sustentável: Brasil 2002 (IDS BRASIL 2002) com o objetivo de "disponibilizar um sistema de informações e acompanhamento da sustentabilidade do padrão de desenvolvimento do País" (INDICADORES DE DESENVOLVIMENTO SUSTENTÁVEL, 2004 p.9).

No ano de 2004, o IBGE publicou uma nova versão dos indicadores de desenvolvimento sustentável (IDS BRASIL 2004), apresentando alterações de modo a melhorar o conteúdo da divulgação, em especial quanto à sua estrutura e ao acréscimo de um conjunto de novos indicadores - a versão 2002 continha 50 indicadores, enquanto a referente a 2004 apresentou 59.

Adotou-se o marco ordenador da CDS/ONU nas duas publicações, com uma simplificação ainda maior, pois foram eliminados os sub temas e modificou-se, por exemplo, a alocação do sub tema saneamento (originalmente vinculado ao tema saúde, dentro da dimensão social) que passou a ser tratado como um tema específico dentro da dimensão ambiental (INDICADORES DE DESENVOLVIMENTO SUSTENTÁVEL, 2004). Além disso, "o tema eqüidade foi renomeado para trabalho e rendimento, sendo a questão da eqüidade entre gêneros e raças tratada transversalmente em diversos indicadores da dimensão social" (SCANDAR NETO, 2006 p. 42). A abordagem simplificada em dimensões e temas utilizada pelo IBGE é apresentada através da Tabela 2: 
Tabela 2 - Marco ordenador adotado na publicação de IDS Brasil 2004

\begin{tabular}{|l|}
\hline \multicolumn{1}{|c|}{ Dimensão: Social } \\
\hline Tema \\
\hline População \\
\hline Trabalho e Rendimento \\
\hline Saúde \\
\hline Educação \\
\hline Habitação \\
\hline Segurança \\
\hline \multicolumn{1}{|c|}{ Dimensão: Ambiental } \\
\hline Tema \\
\hline Atmosfera \\
\hline Terra \\
\hline Água doce \\
\hline Oceanos, Mares e Áreas Costeiras \\
\hline Biodiversidade \\
\hline Saneamento \\
\hline \multicolumn{1}{|c|}{ Dimensão: Econômica } \\
\hline
\end{tabular}

\begin{tabular}{|l|}
\hline Tema \\
\hline Quadro Econômico \\
\hline Padrões de Produção e Consumo \\
\hline \multicolumn{1}{|c|}{ Dimensão: Institucional } \\
\hline Tema \\
\hline Quadro Institucional \\
\hline Capacidade Institucional \\
\hline Fonte: INDICADORES ..., 2004 \\
\hline
\end{tabular}

Cabe destacar que a publicação IDS BRASIL 2004 "não apresenta qualquer tentativa de alinhamento dos indicadores segundo o conhecido marco teórico pressão/estado/resposta, que figurava nas primeiras recomendações da CDS/ONU. Esta abordagem é bastante funcional quando aplicada a questões ambientais, mas se mostrou de difícil aplicação quando transportada a outros temas" (INDICADORES DE DESENVOLVIMENTO SUSTENTÁVEL, 2004 
p.13). Além disso, a publicação ressalta que apesar de se espelhar em várias contribuições teórico-metodológicas e de seguir o marco ordenador proposto pela CDS/ONU, o conjunto de indicadores apresentados não segue a uma abordagem específica em termos de marco conceitual.

\section{Estrutura IDS adotada na Suiça}

Durante o período entre 1997 e 1999, o Swiss Federal Statistical Office (SFSO) e a Swiss Agency for the Environment, Forests and Landscape (SAEFL) conduziram um estudo piloto focando em IDS fundamentado naquele proposto originalmente pela CDS/ONU e baseado no modelo PER. No entanto, como anteriormente citado este modelo não se mostrou aplicável aos aspectos sociais e econômicos, bem como não evidenciou as interações entre as diferentes áreas do desenvolvimento sustentável (ALTWEGG et al., 2004).

Consequentemente, em meados do ano 2000 os órgãos SFSO e SAEFL iniciaram o projeto MONET - Monitoring Sustainable Development, cujo objetivo principal seria criar um sistema operacional de indicadores para monitorar a sustentabilidade na Suíça. No final do mesmo ano, a Swiss Federal Office for Spatial Development (ARE) se juntou aos demais órgãos para elaboração de tal projeto.

De acordo com Altwegg et al. (2004 p. 9) tal "sistema deve facilitar a medição, documentação e descrição do estado de progresso na Suíça, bem como sua posição em relação a outros países, a partir do ponto de vista de aspectos social, econômico e ecológico do desenvolvimento sustentável". Para sua elaboração algumas exigências foram consideradas de vital importância, como por exemplo: (1) aderência aos princípios básicos para estatísticas oficiais; (2) flexibilidade - uma vez que o conceito de desenvolvimento sustentável pode sofrer mudanças considerando que tal conceito ainda está em formação, o sistema não pode ser validado indefinidamente; (3) interdisciplinaridade e perspectiva holística - como a sustentabilidade envolve todas as áreas da vida e, em especial, a relação entre as mesmas, o conjunto de indicadores deve usar o conhecimento disponível de várias disciplinas.

O projeto MONET adotou o procedimento ilustrado na Figura 1 para a criação de um sistema de indicadores de modo a evitar o risco de arbitrariedade ou de uma influência de favorecer um determinado grupo de interesse (ALTWEGG et al., 2004).

Figura 1 - Procedimento para criação dos indicadores do projeto MONET

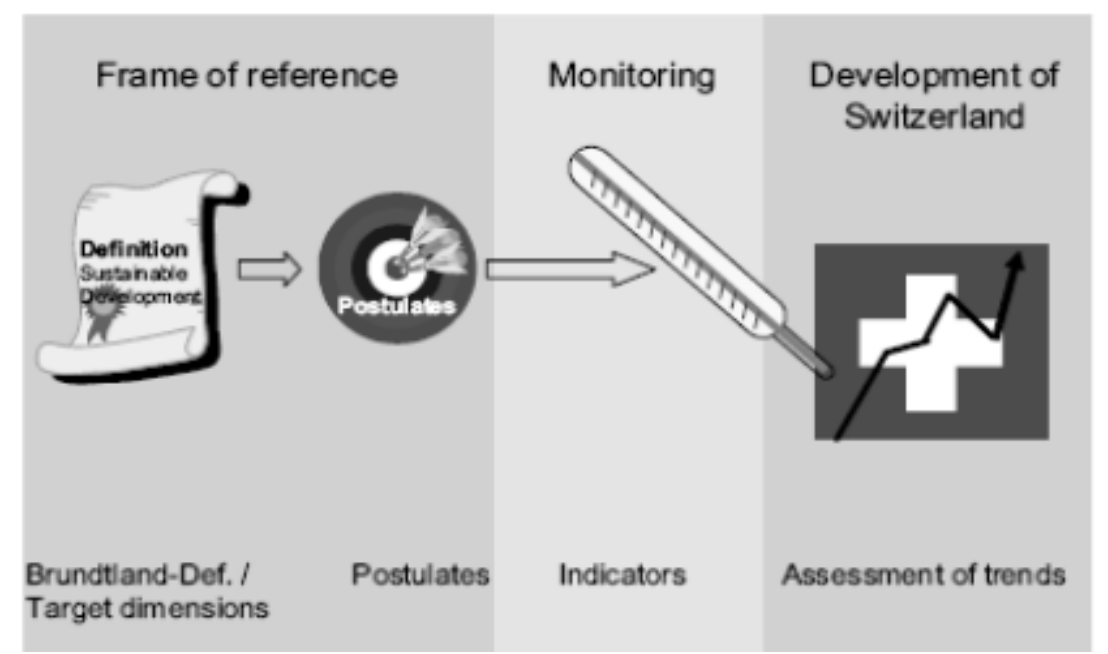

Fonte: ALTWEGG et al., 2004 
O primeiro passo é identificado como a definição de desenvolvimento sustentável, a sua interpretação que leva a definição de dimensões alvos e a transformação destes em postulados. Cabe destacar que a definição utilizada neste projeto é fundamentada naquela constante do Relatório de Brundtland e sua interpretação foi ampliada de acordo com estudos mais detalhados de termos como: sustentável, desenvolvimento, intra e inter-gerações, justiça, necessidades (ALTWEGG et al., 2004).

Posteriormente, passou-se para a definição de dimensões alvos, especificadas como: solidariedade social, eficiência econômica e responsabilidade ambiental. Com relação a isto se ressalta que as três dimensões são geralmente representadas como pilares independentes; no entanto, a visão integradora entre as dimensões deve predominar e o desenvolvimento sustentável deve promover a interface entre os pilares que não devem ser considerados colunas individuais. Em seguida, passa-se para a formulação dos postulados de desenvolvimento sustentável que constituem o quadro de referência que permitirá uma escolha consistente e transparente dos indicadores; destaca-se que tais postulados utilizados no projeto MONET são referentes às três dimensões já mencionadas (ALTWEGG et al., 2004).

"Ao contrário de uma simples de lista de indicadores, um sistema de indicador é baseado em uma estrutura definida claramente que fornece uma estrutura lógica e sistemática para a seleção de indicadores" (ALTWEGG et al., 2004 p. 22). A Figura 2 mostra a representação gráfica da classificação de indicador desenvolvida para o projeto MONET fundamentada no modelo de fluxo de estoque. Tal modelo descreve as dinâmicas de operações de relevância para o desenvolvimento sustentável dentro de um quadro de referência teórico (SCANDAR NETO, 2006).

Figura 2 - Representação gráfica do Modelo MONET

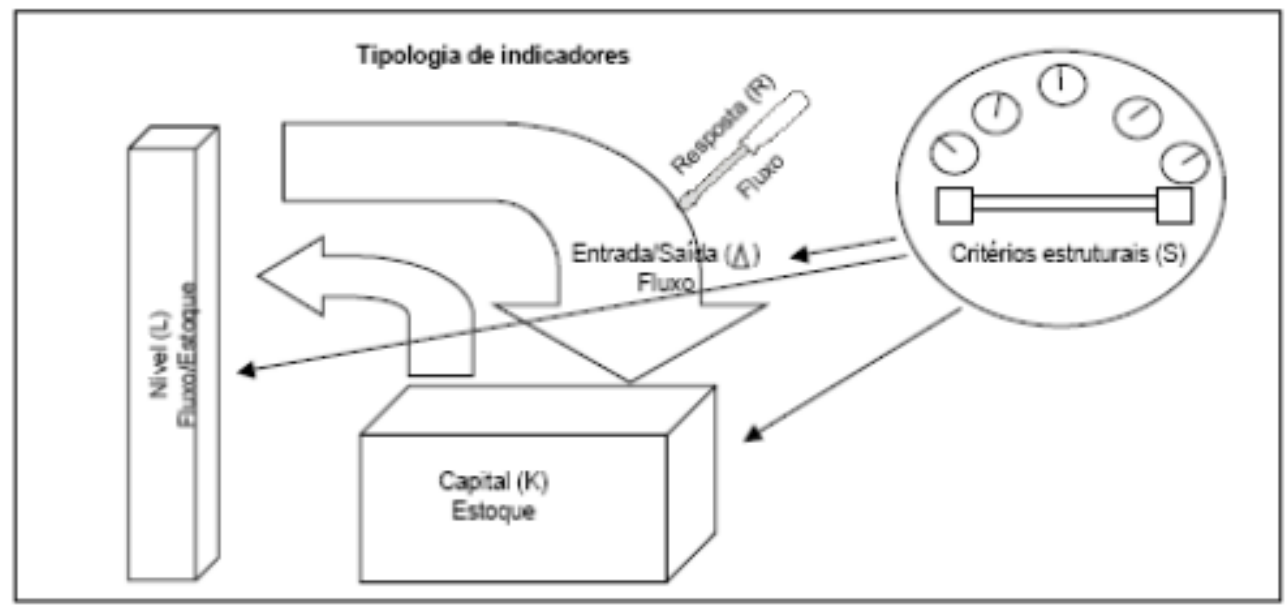

Fonte: GALLOPIN, 2003 apud SCANDAR NETO, 2006

De acordo com Altwegg et al. (2004, p.23) "o modelo apresenta similaridade com o modelo pressão-estado-impacto-resposta usado em alguns sistemas de indicadores. Ao contrário do último, contudo, ele não é específico para os requerimentos de aplicações ambientais, mas é também aplicável aos tópicos social e econômico". A Tabela 3 ilustra o marco ordenador adotado pelo projeto MONET, no qual são listados os 26 tópicos usados e suas relações com os postulados de desenvolvimento sustentável definidos previamente. 
Márcia França R. Fernandes dos Santos, José Antonio Assunção Peixoto e Leyderdavan de Souza Xavier

Tabela 3 - Marco ordenador adotado no projeto MONET

\begin{tabular}{|l|c|c|c|}
\hline \multirow{2}{*}{ Tópico } & \multicolumn{2}{c|}{ Postulados de Desenvolvimento Sustentável } \\
\cline { 2 - 4 } & $\begin{array}{c}\text { Solidariedade } \\
\text { Social }\end{array}$ & $\begin{array}{c}\text { Eficiência } \\
\text { Econômica }\end{array}$ & $\begin{array}{c}\text { Responsabilidade } \\
\text { Ambiental }\end{array}$ \\
\hline Securidade social e prosperidade & $\mathrm{X}$ & $\mathrm{X}$ & \\
\hline Saúde & $\mathrm{X}$ & $\mathrm{X}$ & $\mathrm{X}$ \\
\hline Condições de vida subjetiva & $\mathrm{X}$ & $\mathrm{X}$ & \\
\hline Habitação & $\mathrm{X}$ & $\mathrm{X}$ & \\
\hline Cultura e lazer & $\mathrm{X}$ & $\mathrm{X}$ & \\
\hline Coesão social e participação & $\mathrm{X}$ & $\mathrm{X}$ & \\
\hline Cooperação desenvolvimento & $\mathrm{X}$ & $\mathrm{X}$ & \\
\hline Educação e ciência & $\mathrm{X}$ & $\mathrm{X}$ & \\
\hline Informação & & $\mathrm{X}$ & \\
\hline Securidade física & & $\mathrm{X}$ & \\
\hline Comércio & & & \\
\hline competitividade & $\mathrm{X}$ & $\mathrm{X}$ & \\
\hline Mercados doméstico & $\mathrm{X}$ & \\
\hline Emprego & & & \\
\hline Pesquisa, desenvolvimento & $\mathrm{X}$ & \\
tecnologia & & & \\
\hline Produção & & & \\
\hline
\end{tabular}




\begin{tabular}{|l|c|c|c|}
\hline Consumo & & $\mathrm{X}$ & \\
\hline Mobilidade & $\mathrm{X}$ & $\mathrm{X}$ & $\mathrm{X}$ \\
\hline Materiais, desperdícios e emissões & $\mathrm{X}$ & $\mathrm{X}$ & $\mathrm{X}$ \\
\hline Terra & $\mathrm{X}$ & & $\mathrm{X}$ \\
\hline Água & $\mathrm{X}$ & & $\mathrm{X}$ \\
\hline Ar & $\mathrm{X}$ & & $\mathrm{X}$ \\
\hline Clima & & $\mathrm{X}$ \\
\hline Uso da terra & & $\mathrm{X}$ & $\mathrm{X}$ \\
\hline Biodiversidade & $\mathrm{X}$ & $\mathrm{X}$ \\
\hline Energia & & \\
\hline Florestas & & \\
\hline Fonte: Elaboração própria. Adaptado de ALTWEGG et al., 2004. & \\
\hline
\end{tabular}

\section{COMPARAÇÃO ENTRE OAS ESTRUTURAS DE IDS DO BRASIL E DA SUIÇA}

Por meio da comparação entre os marcos ordenadores adotados pelos IDS de Brasil e Suíça, percebe-se que o modelo suíço permite um maior grau de interação entre as dimensões sociais, ambientais e econômicas do que o modelo brasileiro. 0 projeto MONET adotou uma estrutura aberta, onde é possível criar ligações com outros sistemas de indicadores através da incorporação de indicadores existentes dentro do sistema (ALTWEGG et al., 2004).

Por outro lado, o IDS BRASIL 2004 apresenta as dimensões da sustentabilidade sem conexões umas com as outras. Isto pode ser justificado pelo fato da publicação não adotar um marco conceitual definido, enquanto que o modelo suíço parte de um quadro de teórico metodológico bem definido conforme ilustrado na Figura 1.

Para auxiliar no entendimento da integração entre as diferentes dimensões, o IDS BRASIL 2004 apresenta uma matriz de relacionamento ilustrada na Figura 3. A matriz propõe possíveis ligações existentes entre os diferentes indicadores alocados nos diversos temas, de uma maneira análoga a apresentada pelo Projeto MONET, na Tabela 3. No entanto, a publicação brasileira destaca que "é possível encontrar nexos de inter-relacionamento associando a maioria das questões contempladas nos indicadores. Os relacionamentos apontados, entretanto, estão restritos às relações mais diretas. Muitas já são bastante estabelecidas e têm referência em estudos específicos, outras são indicações de caráter teórico e derivadas apenas de apreciação qualitativa" (INDICADORES DE DESENVOLVIMENTO SUSTENTÁVEL, 2004 p.14). 
Figura 3 - Matriz de Relacionamento IDS BRASIL 2004

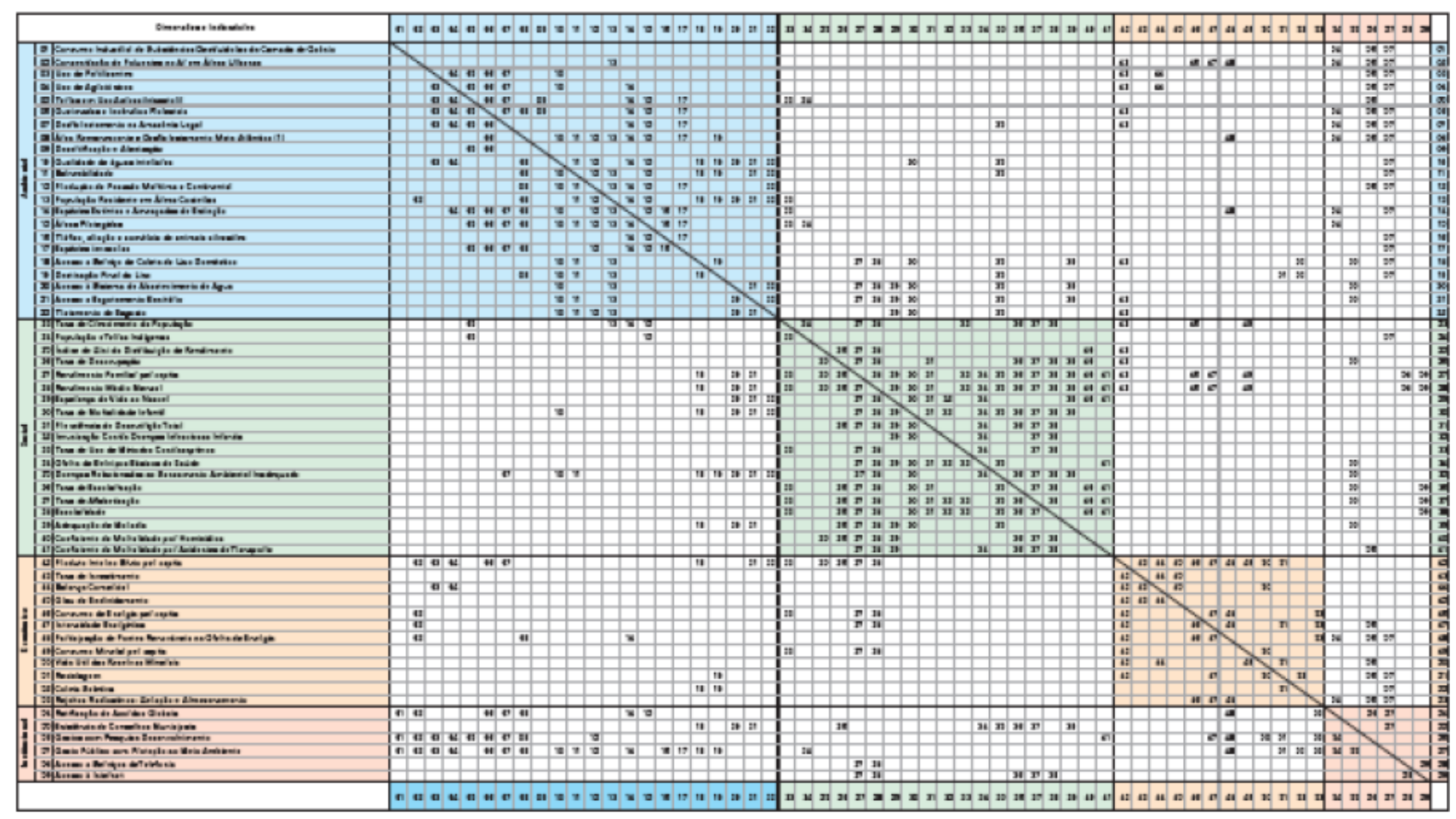

Cabe destacar que assim como no Brasil, a Suíça também partiu do modelo de IDS proposto pela CDS/ONU; contudo, através de estudos piloto descobriu que tal sistema de indicadores era apenas parcialmente aplicado ao monitoramento do desenvolvimento sustentável e decidiu por criar um sistema próprio que melhor se ajustasse as particularidades do país. Outros países como Alemanha e Suécia também elaboraram sistemas de indicadores construídos levando em consideração as suas necessidades específicas (ALTWEGG et al., 2004).

Outra questão relevante diz respeito à disponibilidade de dados e estatísticas referentes à sustentabilidade com relação à Suíça e ao Brasil, considerando-se a heterogeneidade entre os mesmos, uma vez que o Brasil apresenta um território e uma biodiversidade muito maior do que a Suíça (existem outras especificidades como o nível de industrialização e a estrutura econômica, dentre outros). Além disso, há o aspecto da comparabilidade dos dados, uma vez que grande parte dos temas relacionados ao desenvolvimento sustentável pode ser quantificada, mas algumas vezes não podem ser diretamente comparadas como, por exemplo: as perdas da biodiversidade no Brasil não podem ser comparadas com as da Suíça em face das diferenças mencionadas.

\section{CONCLUSÕES}

O presente trabalho destacou a estrutura dos indicadores de desenvolvimento sustentável adotada pelo Brasil e Suíça através das publicações emitidas pelo IBGE e órgãos suíços. Compararam-se os marcos ordenadores adotados nas propostas de construção de indicadores de desenvolvimento sustentável, avaliando-se os aspectos que apresentam convergências e divergências do ponto de vista teórico e metodológico, levando-se em consideração as particularidades de cada país.

O estudo revelou que a publicação IDS BRASIL seguiu o marco ordenador proposto pela CDS/ONU, com algumas simplificações, e destacando que o conjunto de indicadores 
apresentados não segue a uma abordagem específica em termos de marco conceitual. Tal abordagem, entretanto, não evidencia de modo claro as interações entre as dimensões da sustentabilidade consideradas.

Em contrapartida, a Suíça optou por construir uma estrutura de indicadores de desenvolvimento sustentável própria, de modo se ajustar melhor às demandas do país. 0 projeto foi denominado MONET e foi elaborado um marco conceitual a partir do modelo de fluxo de estoque. Além disso, a especificação dos marcos ordenadores procurou favorecer a integração entre as três dimensões alvos do desenvolvimento sustentável Suíço: solidariedade social, eficiência econômica e responsabilidade ambiental.

Outra questão destacada no trabalho diz respeito à grande heterogeneidade entre os países estudados, considerando elementos específicos como nível de industrialização, estrutura econômica, espaço geográfico, organizações, cultura, tecnologia e nível de educação da população dentre outros. Aqui cabe destacar a importância de como os atores sociais e a tecnologia afetam o espaço a sua volta e alteram as práticas sociais, consequentemente promovendo restrições na mensuração do grau de sustentabilidade das diferentes nações.

Por fim, a solução adotada pela Suíça de elaborar um ferramental próprio para mensurar o estado de progresso, com relação à sustentabilidade, parece ser a mais adequada, pois considera as especificidades de seu país na construção da estrutura de indicadores de desenvolvimento sustentável. As nações são diferentes entre si, e não podem seguir como uma "receita de bolo" a estrutura proposta pela CDS/ONU, que deve ser encarada como um guia norteador a ser adaptado a realidade de cada nação para servir, assim, como um eficaz instrumento para medição do grau de sustentabilidade de cada Estado.

\section{BIBLIOGRAFIA}

ALTEGG, H.; ROTH, I; SCHELLER, A. Monet measuring sustainable development: final report methods and results. Neuchâtel: Swiss Federal Statistical Office, 2004. Disponível em: <http://www.bfs.admin.ch>. Acesso em: abr. 2007.

BELLEN, H.M.V. Indicadores de sustentabilidade: uma análise comparativa. Rio de Janeiro: Editora FGV, 2007.

CSD THEME INDICATOR FRAMEWORK FROM 2001. Disponível em:<http://www.un.org/esa/sustdev/natlinfo/indicators/isdms2001/table_4.htm>. Acesso em: abr. 2007.

GIDDEnS, A. A Constituição da Sociedade. São Paulo: Editora Martins Fontes, 2003. INDICADORES DE DESENVOLVIMENTO SUSTENTÁVEL: Brasil 2004. Rio de Janeiro: IBGE. 2004. 400 p. (Estudos e pesquisa. Informação geográfica, n. 4).

INDICATORS OF SUSTAINABLE DEVELOPMENT: GUIDELINES AND METHODOLOGIES. New York: United Nations, Department of Economics and Social Affairs, 2001. Disponível em:< www.un.org/esa/sustdev/publications/indisd-mg2001.pdf>. Acesso em: abr. 2007.

MARTINS, A.R.P. Desenvolvimento Sustentável: uma análise das limitações do índice de desenvolvimento humano para refletir a sustentabilidade ambiental. Rio de Janeiro, 2006, 127f. Dissertação (Mestrado) - Engenharia de Produção, Universidade Federal Fluminense, Niterói, 2006. 
RIBEIRO, N. Indicadores de desenvolvimento sustentável - Metodologia e experiências. 4o Seminário Fluminense de Indicadores, 2004. Cadernos de textos. Rio de Janeiro: Fundação CIDE, 2004, 116 p.

SACHS, I. Desenvolvimento sustentável, bio-industrialização descentralizada e novas configurações rural-urbana. Os casos da Índia e do Brasil. In: VIEIRA, P.F. \& WEBER, J. (orgs.). Gestão de Recursos Naturais Renováveis e Desenvolvimento: Novos Desafios para a Pesquisa Ambiental. São Paulo: Cortez, 1997.

SANTOS, M. A Natureza do Espaço. 4⿳亠丷a edição. São Paulo: Editora da Universidade de São Paulo, 2006.

SCANDAR NETO, W.J. Indicadores de desenvolvimento sustentável no Brasil. 4 Seminário Fluminense de Indicadores, 2004. Cadernos de textos. Rio de Janeiro: Fundação CIDE, 2004, $116 \mathrm{p}$.

SCANDAR NETO, W.J. Síntese que organiza o olhar: uma proposta para construção e representação de indicadores de desenvolvimento sustentável e sua aplicação para os municípios fluminenses. Rio de Janeiro, 2006, 110 f. Dissertação (Mestrado) - Estudos Populacionais e Pesquisas Sociais, Escola Nacional de Ciências Estatísticas, Rio de Janeiro, 2006.

VIEIRA PINTO, A. V. 0 Conceito de Tecnologia. Volume I. Rio de Janeiro: Editora Contraponto, 2005. 